\title{
Acellular versus whole-cell pertussis vaccines
}

$\mathrm{T}$ HE PROSPECT OF A NEW ACELLULAR PERTUSSIS VACCINE has been a hot topic of discussion by both the Canadian Paediatric Society's Immunization and Infectious Disease Committee, and the National Advisory Committee on Immunization for a number of years. This promise of a new improved vaccine with less side effects being 'just around the corner' has been circulating for over five years. When can we realistically expect a replacement for the whole-cell pertussis vaccine?

The whole-cell pertussis vaccine has been used in Canada for over 50 years and is responsible for the reduction of pertussis cases by over 90\% (1). Because of a high rate of adverse reactions associated with the vaccine, considerable research has taken place to develop a less reactogenic and equally effective vaccine. Much of the impetus for this research has been the concern that pertussis vaccine could cause significant and permanent neurological damage. Recent reviews of these data do not support such an association (2) but the desire for an alternate vaccine continues because of the high rate of minor local and systemic adverse reactions following pertussis immunization (3).

Many of the adverse reactions have been attributed to contaminating constituents and products of the causative bacterium Bordetella pertussis present in the whole-cell vaccine. New 'acellular' vaccines are being formulated which use purified antigens of the bacteria which have been shown to induce protective immunity in animals. These so-called protective antigens which are candidates for inclusion in new pertussis vaccines include pertussis toxin (in a toxoided form), filamentous hemagglutinin, fimbriae and a $69 \mathrm{kDa}$ membrane protein.

Acellular pertussis vaccines have been in widespread use in Japan for almost 10 years and have successfully controlled whooping cough in the immunized population. Two of these vaccines were tested in Sweden in a large efficacy study in the late 1980s. Although effective in protecting infants against typical whooping cough, there was some concern that the vaccines were less effective than the whole-cell vaccine (which unfortunately was not included in the study) (4). Since that time, a number of new acellular vaccines have completed early clinical studies. The efficacy of several of these vaccines will be tested in large studies either underway or soon to begin in a number of countries. However, these studies will not be completed before the end of 1995 and licensure of the vaccines (if they prove to be effective) cannot be expected until 1996.

On a related note, large local reactions are proving to be troublesome for recipients of booster doses of conventional diphtheria/pertussis/tetanus (DPT) vaccine. A recent study showed that $71 \%$ of children given a preschool (fifth) dose of DPT vaccine developed large injection site reactions, and soreness causing arm immobility occurred in $8 \%$. Projected to the 400,000 children across Canada who receive this vaccine annually prior to school entry implies that over 30,000 have arms temporarily immobilized by pain. Fortunately, local symptoms resolve within a few days and are not usually accompanied by systemic adverse effects. The cause likely rests with changes made to the vaccine when alum-containing products were introduced after 1980. High diphtheria toxoid content has been identified as a contributor to vaccine reactions (5) but other constituents such as pertussis vaccine and aluminum phosphate may also be important. Acellular pertussis DT vaccines might offer an early solution. Licensure is pending in the United States for such products to be used for booster doses only; even greater justification for this interim measure might exist in Canada if new vaccines reduce local reactions.

Until acellular vaccines become available, all efforts should be made to ensure complete compliance with current recommendation for the whole-cell pertussis vaccine which has been successful in limiting the morbidity and mortality of pertussis in Canada. Deferral of 
pertussis immunization should be limited to those infants who meet valid contraindications for pertussis vaccine (6).

\section{REFERENCES}

1. Varughese P. Incidence of pertussis in Canada. Can Med Assoc J 1985;132:1041-2.

2. Scheifele D. Pertussis vaccine and encephalopathy after the Loveday trial. Can Med Assoc J 1988;139:1045-6.

3. Cody CL, Baraff LJ, Cherry JD, et al. Nature and rates of adverse reactions associated with DTP and DT immunizations in infants and children. Pediatrics 1981;68:650-60.

4. Ad Hoc Group for the study of pertussis vaccines.

Placebo-controlled trial of two acellular pertussis vaccines in Sweden - protective efficacy and adverse events. Lancet 1988;i:955-60.

5. Scheifele DW, Meekison W, Grace M, et al. Adverse reactions to the preschool (fifth) dose of adsorbed diphtheria-pertussis-tetanus vaccine in Canadian children. Can Med Assoc J 1991;145:641-7.

6. National Advisory Committee on Immunization; Canadian Immunization Guide. 1989:78-85.

S Halperin, MD Halifax, Nova Scotia DE Scheifele, MD Vancouver, British, Columbia NE MacDonald, MD, FRCPC Ottawa, Ontario 


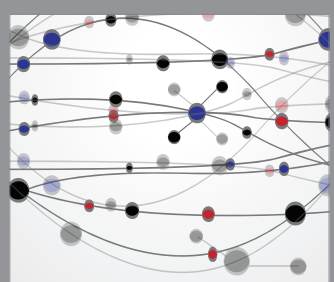

The Scientific World Journal
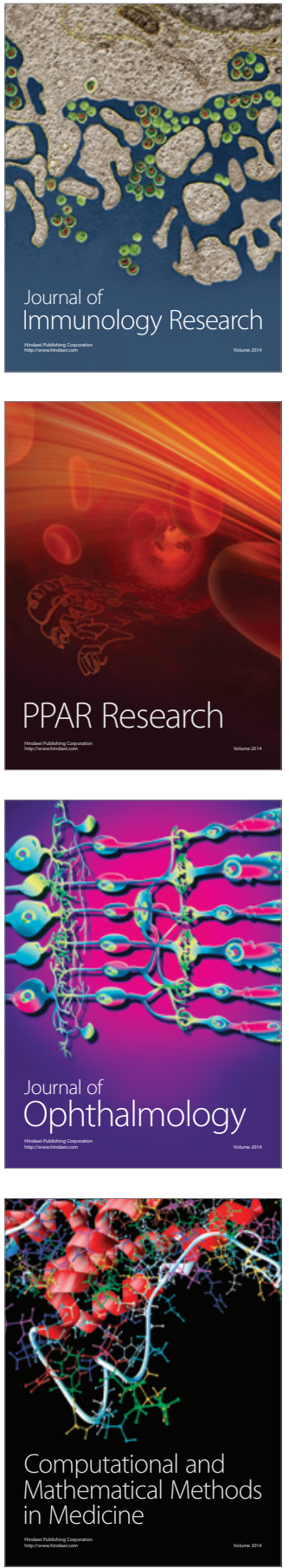

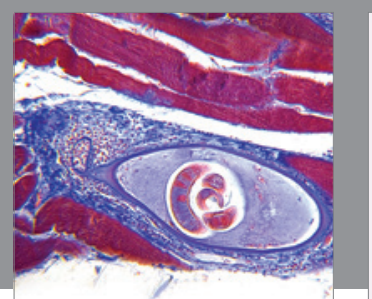

Gastroenterology Research and Practice

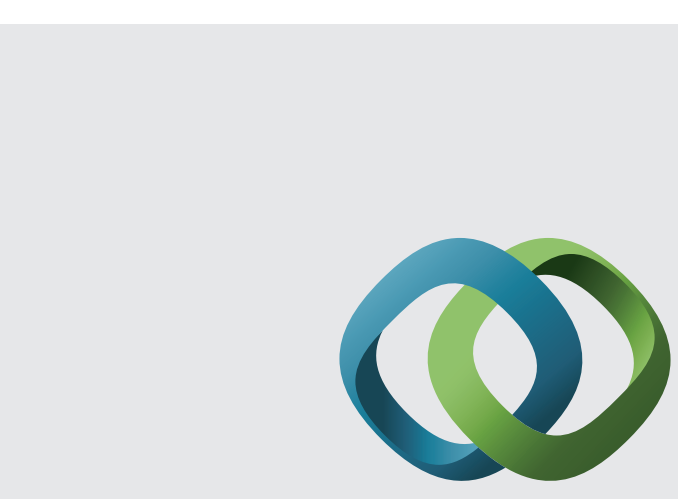

\section{Hindawi}

Submit your manuscripts at

http://www.hindawi.com
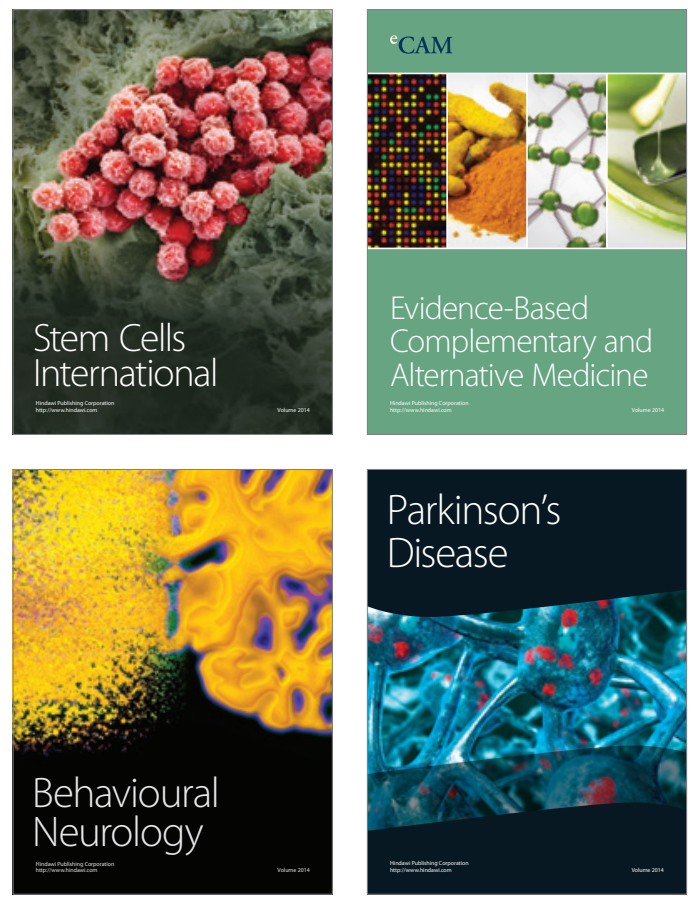
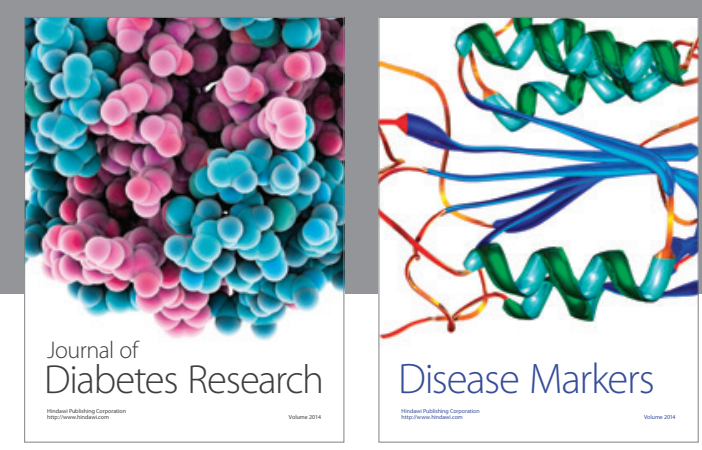

Disease Markers
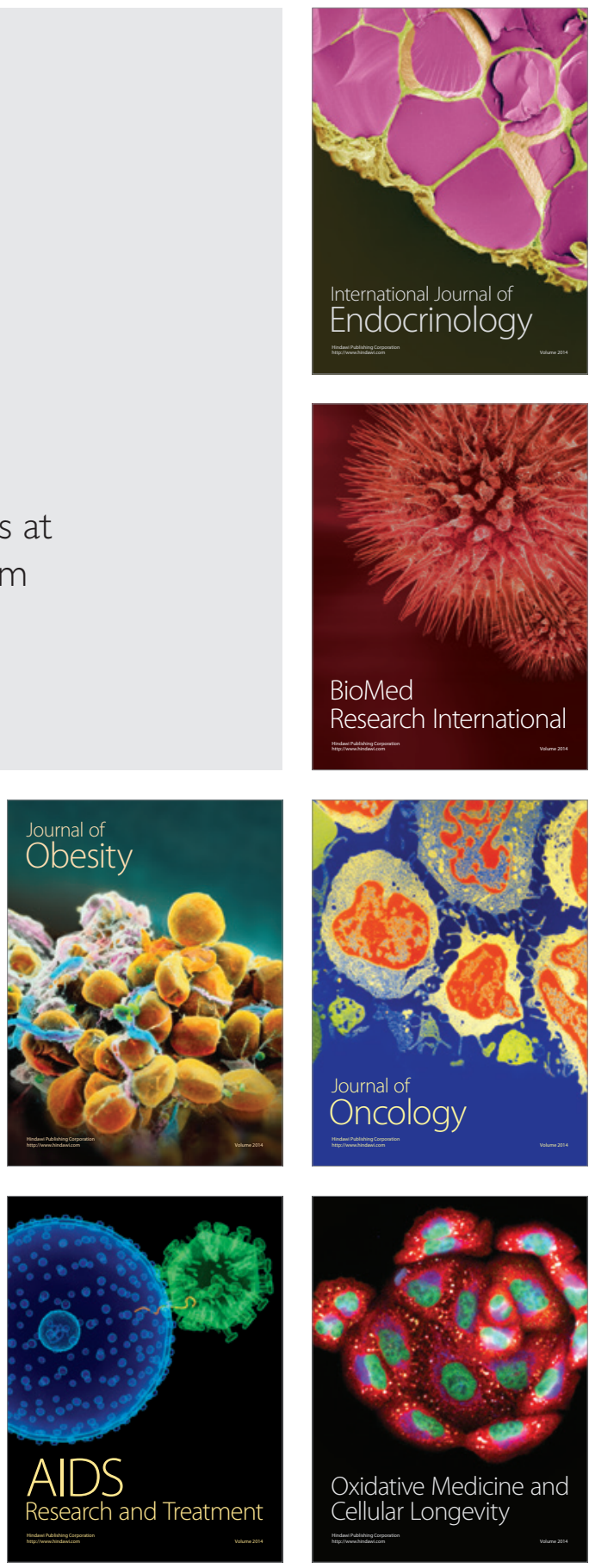